\title{
A BALANCE-BY-DEPTH METHOD FOR THE PHOTOELECTRIC MEASUREMENT OF THE VERTICAL EXTINCTION COEFFICIENT OF WATER
}

\author{
By W. R. G. Atkins, Sc.D., F.Inst.P., F.R.S., H. H. Poole, Sc.D., \\ and F. J. Warren, A.I.P.R.E. \\ From the Plymouth Laboratory
}

(Text-fig. I)

When discussing the programme of work with Mr F. S. Russell, F.R.S., he stressed the importance of being able to make routine measurements of the clearness of the water quickly and with relatively inexpensive apparatussomething more accurate than measurements of the visibility depth of the Secchi disc. The following method is offered as a solution of this; it has several advantages; but it is naturally limited in its range as compared with the standard potentiometer method used here since I924.

\section{OUtLINE OF THE MethoD}

It is now possible to obtain selenium rectifier cells of high sensitivity which with low-resistance galvanometers give curves relating current and light intensity that are almost straight lines up to about one milliampere. Thus if two cells give the same current in fairly bright light, in half, a quarter, or one-tenth of the intensity they will also agree. This will hold even if there is some curvature in the above relation, provided that the characteristic curves of the two cells are similar. Accordingly, connecting two such cells, positive to negative in a circuit (Fig. I), and reducing the illumination on the more sensitive by an iris diaphragm or an opaque varnish on one of the diffusing opals mounted over each, one can use a cheap 0-50 microammeter to indicate balance. Ordinary sensitive galvanometers cannot be used at sea, and the specially balanced type developed for work at sea is expensive. The microammeter, resistance $925 \mathrm{ohms}$, is mounted as a bridge between the two circuits-as in the Campbell-Freeth method-and, since when balanced no current flows through it, its resistance is immaterial. A current does flow, however, in the cell circuit, and were there large temperature differences between the two cells some error might be occasioned. The cells are connected positive to negative, since in the reverse position, at balance, no current flows in the cell circuit and the arrangement is in effect equivalent to open circuit on a potentiometer. This 
would be the best method for balance with thermopiles, but it is not so with rectifier cells, because the internal leakage then becomes relatively very important, and the cell voltages tend towards saturation in bright light.

Selenium rectifier cells are not stable, and undergo a diminution in internal resistance with age, very slow under good conditions, quite rapid when exposed to damp and high temperature. The photometer cases should contain welldried silica gel to absorb included moisture.

It is convenient to use the more sensitive of the pair of cells for use in the sea, mounted as usual in a water-tight gun-metal or brass box, the other being mounted in a case suitable for exposure on deck. Each cell case has over its plain glass a green glass transmitting no red, and an opal-flashed diffusing glass. The uppermost should be flush with the rim so as not to cut off lowangle light. As usual the sea cell is suspended by a bridle with two wires, to which the twin-cored rubber cable is attached by a wide loop, so as not to cast

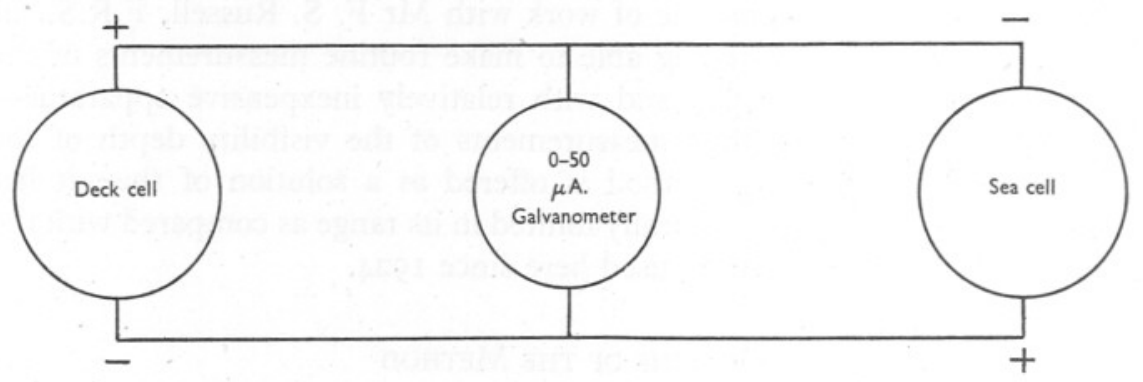

Fig. I.

much shadow. It was possible to bring the pair of cells, as mounted, to exact equality by applying a little opaque varnish to the under side of the deck-cell opal. The deck cell was the more sensitive when mounted. Placing similar pairs of opal discs over each reduced the illumination equally, and balance was maintained right down to $6 \%$ of the initial current.

For use at sea the deck cell should be placed in gimbals.

Having equalized the cells in air an additional surface-flashed opal can be placed on the deck cell and the sea cell lowered till balance is again obtained. This depth is noted on a metre wheel. The percentage illumination at that depth then equals the percentage transmission of the opal. We cannot, however, use this reading to find the vertical extinction coefficient of the water unless we apply an uncertain correction for surface loss and reflexion error, so we must make a second balance at a greater depth with a more opaque disc on the deck photometer. The latter disc is opalized throughout.

It is, however, better to eliminate surface effects by using an opaque varnish, applied to the under-surface of the deck-cell opal, to reduce the sensitivity so that without any extra opal on the deck cell a balance can be found by lowering 
the sea cell to about one metre below the surface. The ship should be stern to sun so as to cause as little shading as possible.

The sequence of operations with our apparatus is then as follows. The cells are balanced with the sea cell at say $0.9 \mathrm{~m}$. below the surface. The illumination is then called $100 \%$. A flashed opal, $A$, transmitting $6 \mathrm{I} \cdot 8 \%$, is placed on the opal of the deck cell; the sea cell is lowered to balance and depth noted. $A$ is replaced by $C$, a thick solid opal transmitting (when over the deck-cell opal) $32.3 \%$, and the depth for balance is observed. $A$ is now placed over $C$, forming a combination which, when over the deck-cell opal, transmits $2 \mathrm{I} \cdot \mathrm{I} \%$. Another solid opal $B$ is then added; the combination $A+B+C$ transmits II $.0 \%$.

We thus have observations of the depths at which the light intensities are $6 \mathrm{I} \cdot 8,32 \cdot 3,2 \mathrm{I} \cdot \mathrm{I}$ and $\mathrm{II} \cdot 0 \%$, of that $0.9 \mathrm{~m}$. below the surface.

The vertical extinction coefficient $\mu_{v}$ is obtained from

$$
\mu_{v}=\frac{2 \cdot 303}{d}\left(\log _{10} p_{1}-\log _{10} p_{2}\right),
$$

where $d$ is the difference in depth, in metres, between the two points at which the percentage values of the balance depth illumination are found. This method has the advantage that instead of measuring air and under-water illuminations in quick succession and obtaining an average on which to base the ratio, the latter is obtained immediately, since changes in illumination. affect both cells equally. The use of the green filter restricts the measurement to a fairly narrow band. This was used since $\mu_{v}$ is dependent upon wave-length and green has the greatest transmission in coastal waters. Were the filter not used there would be a fictitious alteration in $\mu_{v}$ with depth, as the red-and later the blue-are cut off.

Since in the above formula the values of $p$ are constants for the opals and their combinations, one can obtain a factor for each, which has only to be divided by the corresponding value for $d$. Table I shows the transmissions of the opals and their combinations. These are not multiplicative, but must be determined for each. This was done using a Weston rectifier cell which gave a rectilinear relation between current and illumination up to over $4 \mathrm{~mA}$. when tested with a Io $\Omega$ galvanometer on photometer bench and by the use of opals in full daylight on the roof, using a $2 \mathrm{~mm}$. red-free Schott VG9 or a Chance's very similar green glass beneath the permanent opal disc. The opals and combinations selected as most appropriate for use at sea are marked with an asterisk, also the factors which have to be used for the most suitable ranges of transmission as shown in the table, which may serve as a guide for the choice of the combinations with opals of different transmission.

With a homogeneous liquid and approximately monochromatic light the relative reduction in illumination for equal increments in depth would be equal. It would be an advantage to approximate this by the use of opals; it is also 
obviously best to have a good interval between the observations. The series selected for use, namely opals $A, C, A+C, A+C+B$ gives reductions in illumination as follows (each calculated taking the previous illumination as I00 \%), $A 6 \mathrm{I} \cdot 8, C 52 \cdot 3 \%$ (namely $C$ transmits $32.3 \%$ or $52 \cdot 3 \%$ of $6 \mathrm{I} \cdot 8$ ); similarly, for $A+C, 65 \cdot 4$ and for $A+C+B 52 \cdot 2 \%$. The intervals are thus well spaced.

\section{Table I. Relative Transmissions and Factors of Different Filters and Combinations of Filters}

\begin{tabular}{|c|c|c|c|}
\hline Light filter & $\begin{array}{c}\text { Transmission } \\
(\%)\end{array}$ & Interval & Factor $f$ \\
\hline Flashed opal $A^{\star}$ & $6 \mathrm{r} \cdot 8$ & Datum level to $A$ level* $^{\star}$ & $0.48 I^{\star}$ \\
\hline Thick solid opal $C^{\star}$ & $32 \cdot 3$ & Datum level to $C$ level & $I \cdot I_{30}$ \\
\hline Thin solid opal $B$ & $3 I \cdot 2$ & Datum level to $B$ level & $I \cdot I 65$ \\
\hline$(A+C)^{\star}$ & $2 I \cdot I$ & Datum level to $(A+C)$ level & I.554 \\
\hline$(A+B)$ & $20 \cdot 6$ & Datum level to $(A+B)$ level & $\mathrm{I} \cdot 580$ \\
\hline$(B+C)$ & I6. I & Datum level to $(B+C)$ level & $I \cdot 826$ \\
\hline$(A+B+C)^{\star}$ & II $\cdot 0$ & $\begin{array}{l}\text { Datum level to }(A+B+C) \text { level } \\
A \text { level to } C \text { level`}\end{array}$ & $\begin{array}{l}2 \cdot 208 \\
0.649^{\star}\end{array}$ \\
\hline & & $A$ level to $B$ level & 0.684 \\
\hline & & $C$ level to $(A+C)$ level* & $0.426^{\star}$ \\
\hline & & $C$ level to $(A+B)$ level & 0.450 \\
\hline & & $C$ level to $(B+C)$ level & 0.696 \\
\hline & & $(A+B)$ level to $(A+B+C)$ level & $\begin{array}{l}0.052^{n} \\
0.628\end{array}$ \\
\hline & & $(B+C)$ level to $(A+B+C)$ level & 0.381 \\
\hline
\end{tabular}

Notes: The vertical extinction coefficient per metre for a depth interval between two levels at which the illuminations are $p_{1}$ and $p_{2} \%$ of that at datum level, respectively, is $f / d$, where the factor $f=2.303\left(\log _{10} p_{1}-\log _{10} p_{2}\right)$.

The filters and combinations marked with asterisks give convenient intervals which would not differ very greatly in thickness in uniform water. These intervals are also marked with asterisks.

\section{WORK AT SEA}

A comparison was made between this method and our standard potentiometer method using the top cell of our cube photometer, mounted beneath similar green glass and opal. It was found necessary to reduce the sensitivity of the deck cell so that in the position of balance, without extra opal in air, the sea cell remained under water always, whether the sun were shining or not. On account of shading from the ship, the under-surface balance position is necessarily higher when the sun is obscured.

To reduce the error due to drift, final measurements were made by a quick drop to an approximately ascertained position. For the same reason a $7 \mathrm{lb}$. weight was slung below the cell, as the latter was far lighter than the cube photometer.

The method is quick, the depths of balance for the four standard opals and combinations were done twice in Io min., and with the added weight the preliminary run and the quick drop agreed very closely.

The comparison was made at station $\mathrm{L}_{4}$, between Plymouth and the Eddystone, in $55 \mathrm{~m}$. of water. The light was very variable, which made 
accurate work with the standard method rather difficult. The agreement was as close as could be expected. The standard method gave $\mu_{v}=0$. II I over the depth range $5-20 \mathrm{~m}$; no balance could be obtained above $5 \mathrm{~m}$. With the balance-by-depth method the range $0.5-21 \cdot 0 \mathrm{~m}$. gave $\mu_{v}=0.108$ for the quick drop. At $\mathrm{L}_{3}$, near Rame Head, over the same range of illumination, namely down to II.0\% of the subsurface balance point, $\mu_{v}=0.123$, and near the Breakwater Light in Plymouth Sound $\mu_{v}=0.3$ IO.

We desire to express our thanks to Captain Hoodless and the crew of the R.V. Sabella for assistance in handling the gear at sea.

\section{SUMMARY}

Vertical extinction coefficients can be determined in water using selenium rectifier cells and colour filters. The cells are connected positive to negative with a simple 0-50 microammeter across the circuit, as in the Campbell-Freeth method. There is no deflexion when the two points of contact are brought to the same potential. This is done by lowering one cell into the sea to balance the rather less sensitive deck cell. The light reaching the latter is then reduced by the successive addition of opalized plates, to approximately $60,30,20$ and I0 $\%$, and the sea cell is lowered further to balance at each stage. The extinctions can then be calculated by the usual formula from the known percentage transmissions and the observed depths of balance. For each plate or combination a factor may thus be obtained which when divided by the appropriate depth gives the extinction. The method is rapid in operation and the drift error can be rendered negligible. The results agree with those found by the standard potentiometer method, but the applications of the new method are necessarily more limited. 